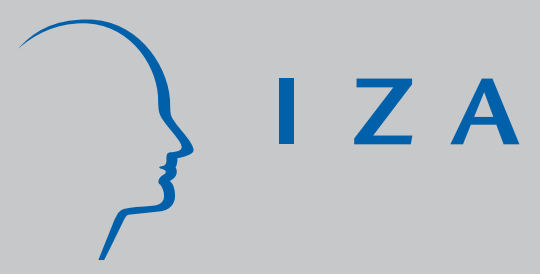

IZA DP No. 1809

On Simplifying the Structure of Labour Demand: An Analysis of the DOT Data

Wim P.M. Vijverberg

J oop Hartog

October 2005 


\title{
On Simplifying the Structure of Labour Demand: An Analysis of the DOT Data
}

\author{
Wim P.M. Vijverberg \\ University of Texas at Dallas \\ and IZA Bonn \\ Joop Hartog \\ University of Amsterdam \\ and IZA Bonn
}

\section{Discussion Paper No. 1809 \\ October 2005}

\author{
IZA \\ P.O. Box 7240 \\ 53072 Bonn \\ Germany \\ Phone: +49-228-3894-0 \\ Fax: +49-228-3894-180 \\ Email: iza@iza.org
}

\begin{abstract}
Any opinions expressed here are those of the author(s) and not those of the institute. Research disseminated by IZA may include views on policy, but the institute itself takes no institutional policy positions.

The Institute for the Study of Labor (IZA) in Bonn is a local and virtual international research center and a place of communication between science, politics and business. IZA is an independent nonprofit company supported by Deutsche Post World Net. The center is associated with the University of Bonn and offers a stimulating research environment through its research networks, research support, and visitors and doctoral programs. IZA engages in (i) original and internationally competitive research in all fields of labor economics, (ii) development of policy concepts, and (iii) dissemination of research results and concepts to the interested public.
\end{abstract}

IZA Discussion Papers often represent preliminary work and are circulated to encourage discussion. Citation of such a paper should account for its provisional character. A revised version may be available directly from the author. 
IZA Discussion Paper No. 1809

October 2005

\section{ABSTRACT \\ On Simplifying the Structure of Labour Demand: An Analysis of the DOT Data}

We analyse the information in the Dictionary of Occupational Titles to characterize the structure of labour demand. Two dimensions, an intellectual factor and a dexterity factor capture most variation in job requirements. Job complexity in relation to Things correlates highly with the dexterity factor. Complexity in relation to Data is intricately interwoven with most other dimensions of jobs. Remarkably, while complexity in relation to Data and to Things associates with extensive training, this does not hold for complexity in relation to People. There is no dichotomy between mathematical and verbal required skills. Poor working conditions are not the exclusive prerogative for workers in low level jobs. This independence provides a good setting for testing the theory of compensating wage differentials and indeed we find a good deal of support.

JEL Classification: J21, J23, J31

Keywords: labor demand structure, job requirements, compensating differentials

Corresponding author:

Joop Hartog

Department of Economics

University of Amsterdam

Roetersstraat 11

1018 WB Amsterdam

The Netherlands

Email: J.Hartog@uva.nl 


\section{Introduction}

Labour supply is routinely differentiated by variables supposed to capture differences in worker quality or productivity, such as education and experience. Labour demand, however, is seldom distinguished by variables that characterise genuine intrinsic differences in the jobs themselves. There may be a distinction by industry, or firm (size), or it may be described as demand for labour by education and experience. Perhaps the closest to focusing on the nature of the work itself is demand by occupation. Yet occupation is only a label, a name, to refer to unspecified traits. While labour supply is measured by variables that allow a ranking, labour demand is usually only measured in a qualitative dimension.

In this paper, we will focus on the genuine differences between jobs as described by job requirements: traits required of workers for successful performance. We will do so by exploiting the wealth of observations in the Dictionary of Occupational Titles (DOT): job requirements and working conditions specified for some 12,000 jobs.

The focus on job requirements has a link to the hedonic (or assignment) literature, where workers differing in qualities are to be matched with jobs differing in job requirements (or complexities) and the wage structure is the instrument to accomplish this (Tinbergen, 1956; Rosen, 1974; Sattinger, 1975; Hartog 1981; Teulings, 1995). But our present goal is much more modest: we just want to lay out the structure of labour demand and investigate how job requirements and working conditions relate; in other words, we want to depict the landscape of labour demand. ${ }^{1}$ Can we summarize the structure of labour demand in a few simple relationships?

We corroborate some standard perceptions of the structure of labour demand, but we also find some interesting surprises. It turns out that we can indeed reduce the dimensionality of labour demand and use a few variables that capture most of the variance in labour demand characteristics. But not all. In terms of required worker abilities, we are able to construct an intellectual factor and a manual factor (dexterity), that jointly capture two thirds of the variance in required abilities. This is a dichotomy that reminds of the old distinction in whitecollar and blue-collar jobs. But the restriction to two factors leaves out one third of the variance, which cannot be captured with constructed factors that have a straightforward interpretation. In other words, the remaining co-variance has no simple structure.

The DOT uses three variables to characterise the activities that have to be performed in jobs: complexity in the relation to Data, to People and to Things. The relation to Things correlates quite low with the other complexities, Data and People correlate modestly (at 0.6). The "matching" relations between required worker traits and nature of the activities are of different complexity. The complexity of worker functioning in relation to Data has a non-linear relation to training, education, aptitudes and temperaments, functioning in relation to Things just relates to Dexterity and training time, functioning in relation to People is determined by the two factors, Intellect and Dexterity, and by separate Temperaments (such as working under stress and making judgments). Complexity in relation with people has a strongly non-linear relationship with training time.

We reduce the many variables used to describe physical demands on workers and environmental conditions to six dimensions in a factor analysis and six separate variables. A presumed structure

\footnotetext{
${ }^{1}$ In a separate paper, we will analyse the link with wages.
} 
of high-level well paid jobs with good working conditions and low-level low-pay jobs is only weakly present in the data. Working conditions are not strongly clustered and they are highly dispersed across job levels as measured by required capabilities. Finally, we find support for compensating wage differentials for some obviously unattractive job traits: exposure to Noise, to Electric shocks and the risk of explosives. The literature gives rather ambiguous results on testing this theory. Our more positive finding may very well relate to the fact that in our data, working conditions are mostly independent of the other variables, an ideal setting for an empirical test. For physical demands, such as Communication and Non-sedentary work, workers take a wage cut, which may indicate that a sufficient number of workers like such conditions.

We will present our data in the next section. Section 3 then explores the structure of job requirements, Section 4 considers the relation with working conditions, and Section 5 concludes.

\section{Utilizing Information from the Dictionary of Occupational Titles}

The Dictionary of Occupational Titles (DOT) contains descriptions and ratings of 12,741 jobs (U.S. Dept. of Labor, 1991). Ratings have been performed by professional job analysts who record the characteristics of each job under the following headings: worker functions, general education development, aptitudes, temperaments, physical demands, environmental conditions, and a few more items. One of the stated aims of the DOT is to provide information about job classifications that employers may consult in order to classify their own vacancies and hire appropriate workers- but the DOT does not specify an appropriate wage for that job.

The first edition of the DOT was published in 1939. It has been updated several times, with revisions in the classification system, additional information about jobs, deletion of obsolete job descriptions, and addition of new jobs. The fourth edition was published in 1977. After a critical review of the DOT content and user friendliness (Miller et al., 1980), two supplements came forth in 1982 and 1986. Further efforts to improvement have led to the fourth revised edition, which came out in 1991. Minor modifications have been made afterwards which are available in electronic form; the version for this study carries a 1992 date.

The objective of DOT is to provide up-to-date information about the nature of jobs in the economy. To achieve this objective, the DOT content must be critically evaluated by job experts in the light of the many technological improvements that occur in the economy. Even if this is done regularly, one may expect the DOT to lag behind, especially in its description of jobs in newly emerging sectors. For research purposes, the DOT information is therefore subject to a measurement error by understating the role of new technology and its required cognitive skills. Nonetheless, the information is unique and potentially very valuable.

DOT jobs are classified into occupational groups that sometimes are identical to the common coding scheme used by the Census Bureau (e.g., 'dentists' or 'mechanical engineering occupations') but at other times differ greatly ('punching, cutting and forming occupations' or 'shearing and shaving occupations'). In principle, DOT's occupational category scheme focuses on the task performed and on the level of complexity with respect to data, people and things. This task may be performed with machinery, with simple tools, or by hand. While some tasks are specific to certain industries (such as textiles and shoe manufacturing), there is no explicit goal to group job descriptions according to their industry affiliation. In contrast, the 1990 Census 
occupational coding retains more of the industry association and distinguishes those working with machines from those working primarily by hand. Thus, the 5643 -digit DOT categories do not translate one-to-one into the 504 3-digit codes used for the 1990 Census.

Under each 3-digit DOT code one usually finds several job descriptions, the majority of which often fit in one Census code; but a few usually belong under other codes. As there are a total of 12,741 of such jobs that must be allocated across the Census codes, coding the DOT jobs into the Census classification scheme is obviously a major task. Fortunately, the National Occupational Information Coordinating Committee (NOICC) in cooperation with, among others, the Occupational Analysis Field Centers of the U.S. Department of Labor (which are responsible for the DOT) developed a database that contains this link. The database is called the NOICC Master Crosswalk and is available on the internet. In this study, we use this database with some relatively minor modifications. ${ }^{2}$

The DOT/Census linkage of occupational codes allows one to compute numerical descriptions of an occupation from the DOT database and enter this information into a database of individuals to be used as an explanatory or even an explained variable. There is an implicit weighting in this linkage process. It is known that the DOT database does not represent a random sample of jobs in the U.S. labor force (Miller, et al., 1980). For example, manufacturing jobs are substantially over-sampled. This nonrandom sampling procedure may be less problematic within each occupational code: there is less variation in the work that defines a specific occupation. Even so, when an occupational job content variable is extracted from DOT, the information content of this variable is subject to the within-occupation sampling probabilities of the jobs that make up the occupation. To give an example, let an occupation ("baker") consist of two types of jobs ("bread baker" and "pastry baker"). Let there be four times as many bread bakers as pastry bakers in the labor force. DOT may well include only one description of each baker job. The description of the average "baker" job should assign four times more weight to the bread baker description. However, such weights are not available, and we are forced to assign equal weights to each job within an occupation.

We also extract information from the DOT database through factor analysis. The lack of random sampling between occupations could severely bias the extracted factors unless some kind of weighting is employed. We solve the problem by tabulating a frequency distribution of wage/salary workers across occupations from the 1990 Census (employing the Census weights in this tabulation), merging this frequency by occupation into the DOT database, and computing a weight as the ratio of the Census frequency divided by the number of DOT jobs assigned to that occupation. The weight measures the relative importance of a given DOT job in the U.S. wage/salary labor force. A comparison of results shows that measured correlations differ substantially according to whether one employs weights. Factor scores are computed from correlations and are similarly influenced.

After dealing with these issues, the end result of the DOT/Census linkage is the merging of

\footnotetext{
${ }^{2}$ When we started with this research, one of us worked on building a linkage. We became aware of the NOICC Master Crosswalk database when about seventy five percent had been linked. In terms of the detailed 1990 Census occupational codes, 54.1 percent of these matched exactly. If one were to distinguish only 19 broad occupational groups, there is an 86.25 percent match. In reviewing some of the differences, it became apparent that the NOICC Master Crosswalk linkage could be questioned in some cases. On the basis of the DOT job description, 227 of the 12741 code links have been changed.
} 
occupational content information with person-specific Census information. For each Census occupational code, the job content represents the arithmetic average across the DOT jobs that have been allocated to it.

There have been a number of previous studies that linked DOT information to the Census codes, using different methodologies. England, Chassie and McCormack (1982) use data constructed by McLaughlin (1975) who selected one occupation from the third edition DOT as representative of a given Census occupation code. Temme (1975) made use of the 1971 Current Population Survey (CPS) which had occupations coded both according to the 1970 Census classification and the third edition DOT occupational titles. This dual coding allowed him to utilize the DOT information in an analysis of CPS individuals. Roos and Treiman (1980) continued this exercise: with the 1971 CPS data and a mapping of third to fourth edition DOT titles, they link the fourth edition DOT information to the 1970 Census codes; see also Cain and Treiman (1981). The data used by Gittleman and Howell (1995) and Rumberger (1981) are constructed in a similar way. The drawback of this method is that the fourth edition contains new occupational titles and is purged from obsolete titles that are still used in the 1971 CPS. Indeed, more than one tenth of the CPS sample cannot be linked. Even so, the average factor scores that Roos and Treiman published have been popular elsewhere; e.g., Sorensen (1989). Thurow and Lucas (1972) and Lucas (1977) uses a 13,778x295 matrix constructed by the U.S. Department of Labor to link the 13778 third edition DOT occupational titles to the 295 categories in the 1960 Census scheme; the cells of this matrix count the number of adults in the 1966 Current Population Survey whose position of work fit into the given cross-classification. This allows Lucas to compute average scores of each DOT variable for each 1960 Census occupation and to use these in an analysis of Survey of Economic Opportunity data. Hartog $(1980,1981)$ links the third edition DOT to the 1960 Census codes by matching identical job titles; he relates the DOT information to median occupational earnings in the 1950 and 1960 Census. Shu et al (1996) use a link between the 1970 Census and the fourth edition of the DOT to make the Census 1960 classification compatible with the Census 1960 classification. England et al. (1994) used the average fourth edition DOT scores for each 1970 Census code, merge this information into a data file with over 50,000 individuals from the 1970 Census whose occupation had also been coded according to the 1980 Census scheme, and then compute average (fourth edition) DOT scores for the 1980 Census scheme. ${ }^{3}$ These averages are then used in a study of individual earnings with National Longitudinal Survey (NLS) data. Parcel (1989) uses the same method and analyzes average occupational wages in the 1980 Census. Kilbourne, England, and Beron (1994) and Kilbourne et al. (1994) use fourth edition DOT scores linked with the 1960 Census codes, computed by Thomas Daymont and Ronald D'Amico, again for use with NLS data. Filer (1989) uses the 1981 CPS survey which was double-coded using the 1970 Census and fourth edition DOT classifications and employs a 1970-to-1980 link of Census codes (which is not described) to come up with DOT variables for use with the 1980 Census wage data.

Obviously, a substantial effort has been devoted to the creation of a DOT-Census link. Thus, why create another one? None of these links used the fourth revised DOT titles. It could be argued that the review of the DOT in the late 1970s (Miller et al., 1980) led to significant

\footnotetext{
${ }^{3}$ If one desires to avoid establishing a new DOT-1980 Census link, this is a clever solution. Some slippage is to be expected, however, since one would probably categorize DOT occupations in different ways when faced with a different Census code categories. As a base, the 1970 and 1980 categories are both too rough. For example, suppose a DOT title carries a score of 5 and ends up in a 1970 Census category with a occupational average of 3.45. When this occupation is recoded according to the 50000 individuals file, it contributes a value of 3.45 (the old group mean) to the mean of the 1980 Census category. A direct link allows the DOT title to contribute a value of 5 to the 1980 Census occupational category.
} 
improvements and makes the fourth revised DOT more relevant than any before, both in the measured variables and in the job titles it contains. Apart from this, it is also more up-to-date. Given the many changes in the economy and technology, links with the 1970 Census codes are not particularly useful anymore. The 1990 Census coding differs in only minor ways from the 1980 scheme, so a link between DOT and the 1980 Census still has some value. But this link should be created directly rather than through a 1970-1980 linkage that invariably causes slippage (see footnote 3) and, by now, is becoming unrepresentative.

The DOT characterizes jobs by seven main types of variables. Full details are given in an Appendix ${ }^{4}$; here we give a short description:

\section{Worker Functions: Data, People, Things}

Worker functions specify at what level a worker is required to function in relation to Data, to People and to Things. The levels are specified as a ranking from the simple to the complex, with each successive level including the simpler level and excluding the more complex level. There are 7 to 9 levels.

\section{Specific Vocational Preparation: SVP}

SVP is defined as the time required by a typical worker to learn the techniques, acquire the information and develop the facility needed for average performance in the job. The definition suggests it refers to broadly defined training or specific experience needed before one may qualify for the job. The training may be acquired at school or at work, and it does not include the orientation time that a fully qualified worker needs to get accustomed to the special conditions of a new job. SVP is measured on a time scale of 9 time intervals.

\section{General Educational Development: GED}

GED embraces formal and informal aspects of education required for satisfactory job performance. It is education of a general nature without specific occupational objective. Ordinarily it is obtained in school but it may also be obtained from experience or self-study. The GED scale has three divisions: Reasoning Development, Mathematical Development and Language Development. There are 6 levels, but for Language Development the two highest levels have been merged into one.

\section{Physical Demands}

This specifies the overall physical strength requirement of a job, specific required body movements (stooping, kneeling) and specific strength applications.

\section{Aptitudes}

Aptitudes specify the particular capabilities and abilities required of an individual in order to perform a task or job duty adequately. There are 11 aptitudes, relating to dimensions of intellectual ability, spatial ability and physical ability, taken from the General Aptitude Test Battery. They are ranked on a five level scale, aiming at intervals of the distribution of that ability in the population.

\footnotetext{
${ }^{4}$ The Appendix is available at www.utdallas.edu/ vijver/DOT.Appendix.pdf
} 


\section{Temperaments}

Temperaments describe different types of occupational situations, such as performing a variety of duties or repetitive cycle operations, or situations involving influencing people in their opinions or attitudes.

\section{Environmental Conditions}

These conditions characterize the work environment: whether it is hot or cold, inside or outside, brings dangers of explosives or toxic conditions etc.

In an extensive appendix, we copy the description of the variables from the DOT and we add characterisation of the dataset by means and dispersions of these variables. We also use information from the Census 1990 and the CPS-NBER 1990 data files. This gives us frequency distributions of jobs which allow us to describe the labour market in terms of frequencies and correlations of the characteristics we distinguish. Elsewhere we explore the link between job characteristics and wages in detail. Here we only make a brief excursion to test the theory of compensating wage differentials, because we found our data particularly suited for this purpose. We use two data sets to consider the robustness of results. As to wages we consider the CPSNBER data more reliable, because the information is based on interviews rather than selfreporting and because the interviewer asks directly for hourly wages on the current job, eliminating the need to calculating them from dividing earnings by usual hours, a notoriously unreliable procedure. The Census asks for annual earnings in the previous year, which for many respondents is less familiar than current wages. We focus the analyses on full-time employees and so we restricted the samples to individuals working between 30 and 70 hours a week, while also requiring at least 4 weeks of work during the year. We excluded individuals under 16 and over 65.

\section{Analyzing the structure of job requirements}

The DOT uses almost 50 variables to characterise the requirements of a job. This is of course a delightful wealth of material. But it is too much to digest into a comprehensible picture of the structure of job requirements. We will acknowledge the difference in types of the variables and then exploit correlations between the variables within the subgroups, and with factor analysis reduce the dimensionality of the dataset. Hence, in this potentially very complex landscape of job locations, we will see if there are some main ridges that dominate the perspective. ${ }^{5}$

Based on the nature of the variables and earlier research (Hartog, 1980), we start with a factor analysis of the Aptitudes and some Temperaments. The Temperament variables included here are selected on grounds that they represent worker characteristics more so than job

\footnotetext{
${ }^{5}$ Reduction of the DOT information by factor analytic methods has been done before. Gittleman and Howell (1995) apply cluster analysis to jobs covered in the 1980 Census and various editions of the CPS. They are interested in applying the segmentation view of the labour market and base their clusters not only on DOT variables, but also on hourly earnings, annual earnings and institutional features like union coverage. Shu, Fan, Li and Marini (1996) link the fourth edition DOT (1977) scores to the jobs in the 1960, 1970 and 1980 Censuses and stress that the underlying factor structure is highly stable over time. Gittleman and Howell discuss a few other applications of factor analysis; none of these uses the DOT 1992 edition.
} 
conditions (such as repetitive work or working alone). We also combine these with the GED variables. These variables mostly refer to all kinds of mental abilities, and searching for a few underlying dimensions is an obvious first step. In columns 2 and 3 of Table 1 , we present results for a factor analysis on the Aptitudes and Temperaments; columns 4 and 5 add GED variables. We only show the first two factors, the ones that we retain for further analysis. With factor analysis on the GATB Aptitudes, the first factor explains 37\% of the variance; the first two explain $64 \% .{ }^{6}$ With a third factor, explained variance would go up to $75 \%$, thus showing the strong intercorrelation of the variables, but this factor is less easily labeled than the other two, so we decided not to use it (its highest factor loading is 0.47 ; moreover, while the first two factors have eigenvalues of 4.41 and 3.30, the third factor has only 1.21). The first factor loads exclusively high on General intellect, on Verbal ability and on Numerical ability. We will dub this factor the Intellect Factor. The second factor loads highest on Motor Coordination, Finger dexterity and on Manual dexterity, and also relatively high on Spatial Orientation and Form Perception. We dub this factor the Dexterity Factor. In columns 4 and 5 of Table 1, we include the GED variables and not unexpectedly, these three variables are smoothly integrated in the factor analysis: they are convincingly subsumed in the Intellect Factor. Similar as before, the first two factors jointly explain $69 \%$ of the variance, with a similar situation as before for the third factor. In both cases, the temperaments give modest factor loadings: the structure is mostly determined by Aptitudes and by GED.

Table 1: Factor analysis of General Educational Development, GATB Aptitudes, and Temperaments ${ }^{\mathrm{a}}$

\begin{tabular}{|c|c|c|c|c|}
\hline \multirow[b]{2}{*}{ Variable } & \multicolumn{2}{|c|}{ Rotated Factor Loadings } & \multicolumn{2}{|c|}{ Rotated Factor Loadings } \\
\hline & Intellect & Dexterity & Intellect & Dexterity \\
\hline Reasoning development & & & 0.954 & 0.055 \\
\hline Mathematical development & & & 0.892 & 0.073 \\
\hline Language development & & & 0.944 & -0.045 \\
\hline Apt: General learning ability & 0.907 & 0.071 & 0.906 & 0.032 \\
\hline Apt: Verbal aptitude & 0.932 & -0.041 & 0.919 & -0.083 \\
\hline Apt: Numerical aptitude & 0.820 & 0.110 & 0.835 & 0.078 \\
\hline Apt: Spatial aptitude & 0.241 & 0.646 & 0.275 & 0.634 \\
\hline Apt: Form perception & 0.293 & 0.724 & 0.307 & 0.708 \\
\hline Apt: Clerical perception & 0.687 & -0.038 & 0.672 & -0.070 \\
\hline Apt: Motor coordination & -0.118 & 0.738 & -0.093 & 0.738 \\
\hline Apt: Finger dexterity & 0.050 & 0.731 & 0.070 & 0.725 \\
\hline Apt: Manual dexterity & -0.363 & 0.690 & -0.322 & 0.706 \\
\hline Apt: Eye-hand-foot coordination & -0.310 & 0.247 & -0.279 & 0.263 \\
\hline Apt: Color discrimination & 0.081 & 0.436 & 0.088 & 0.433 \\
\hline Temp: Directing & 0.598 & -0.241 & 0.589 & -0.267 \\
\hline Temp: Influencing & 0.375 & -0.303 & 0.364 & -0.322 \\
\hline Temp: Expressing feelings & 0.105 & 0.097 & 0.102 & 0.091 \\
\hline Temp: Performing under stress & -0.037 & 0.115 & -0.019 & 0.117 \\
\hline Temp: Precise tolerances & -0.094 & 0.516 & -0.063 & 0.526 \\
\hline Temp: Dealing with people & 0.531 & -0.334 & 0.502 & -0.359 \\
\hline Temp: Making judgments & 0.562 & 0.200 & 0.580 & 0.178 \\
\hline Variance proportion $^{\mathrm{b}}$ & 0.368 & 0.644 & 0.462 & 0.688 \\
\hline
\end{tabular}

\footnotetext{
${ }^{6}$ We use the iterated principal factor method of Stata. The standard principal factor method yielded a series of negative eigenvalues that confuse the interpretation of the percentage of the variance explained by the selected factors.
} 
The DOT data allow us to get a picture of the matching between the required worker qualities and the sort of activities that have to be performed. Worker Functions DPT (Data, People, Things) measure these job duties. In Figure 1, we present the relation between DPT and Intellect and Dexterity in graphical form, with "Balloon Plots": for any given combination of the value of two variables, we represent the frequency of observations by the size of the balloon. These are summary pictures for easy visual inspection of the gross structure of labour demand in terms of key characteristics. In these marginal distributions, with other variables integrated out, Data and Intellect clearly correlate positively, and the same holds for Things and Dexterity. The correlation between People and Intellect is weakly positive, between People and Dexterity weakly negative. The other distributions exhibit no clear correlation.

Figure 1: Frequency Distribution of DTP against Intellect and Dexterity
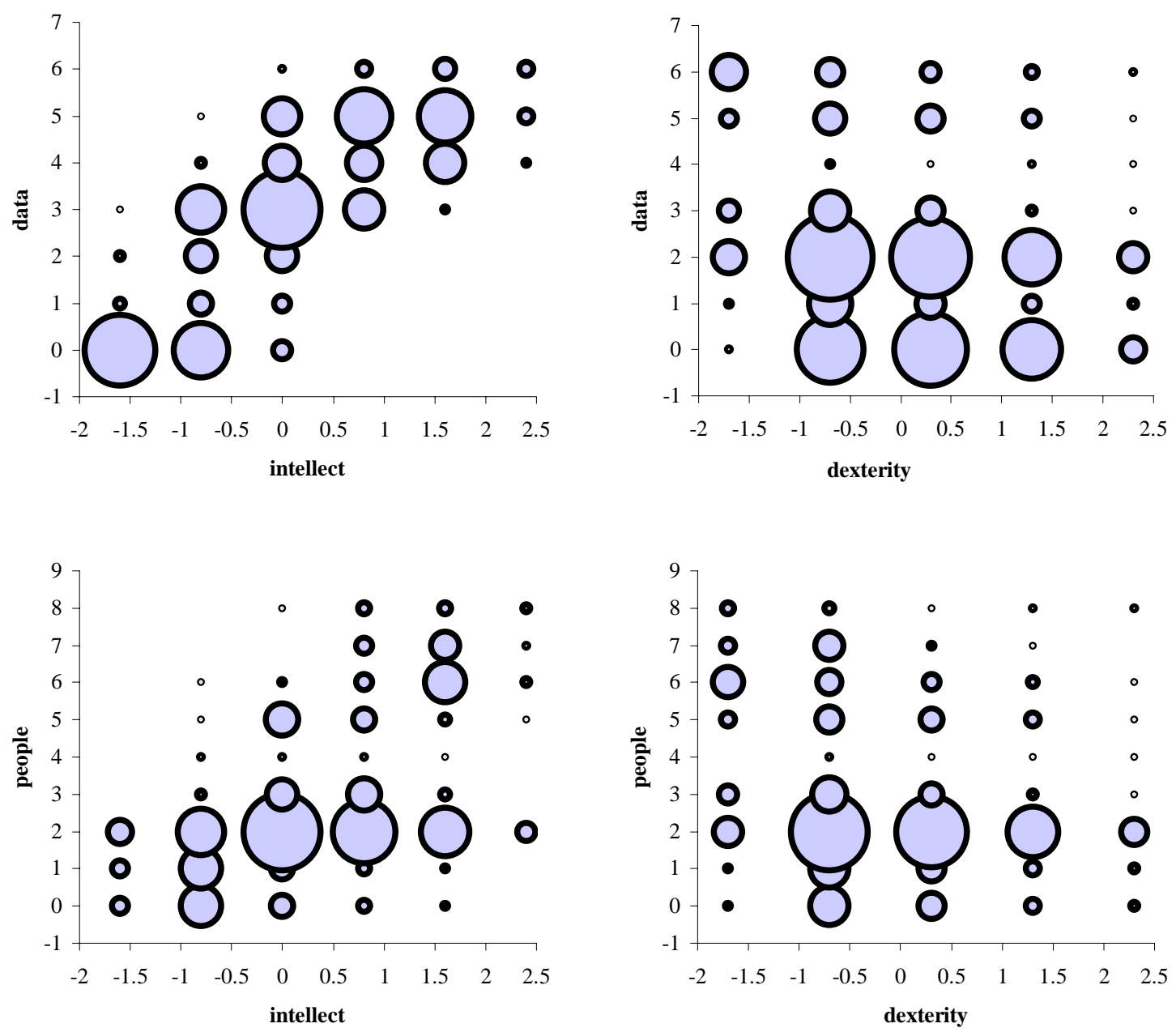

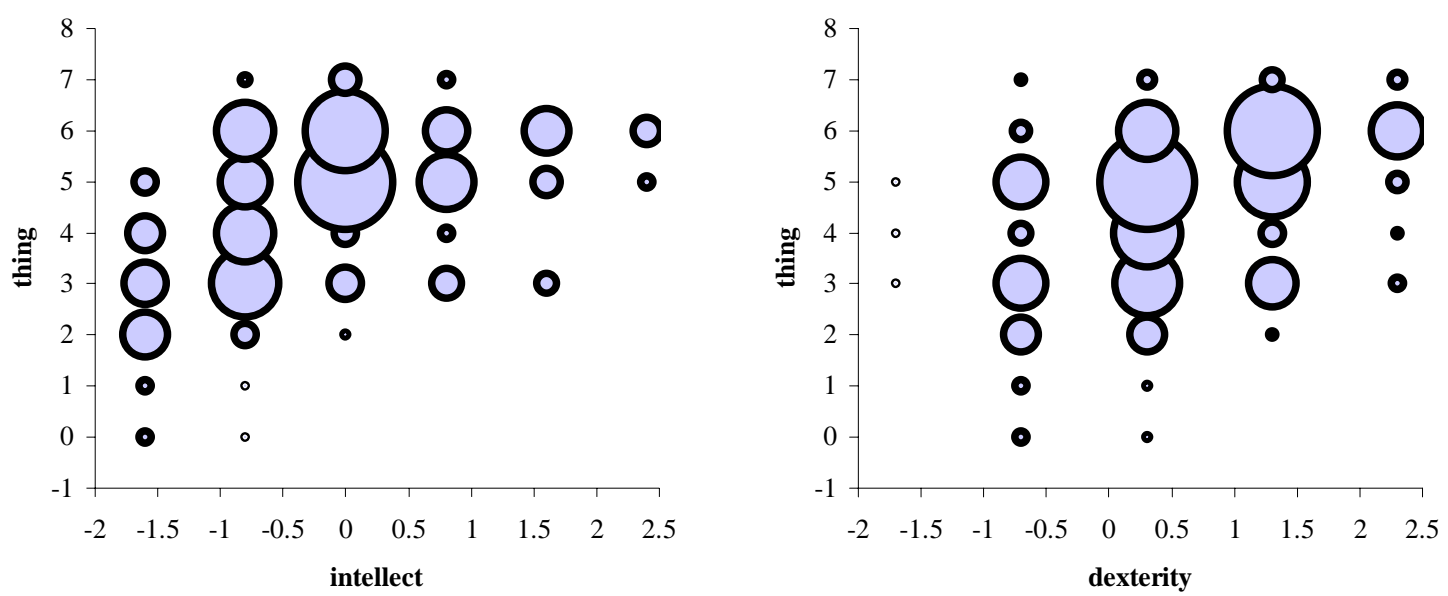

The observations are confirmed by the correlation coefficients in Table 2, where we can also observe other interesting patterns. The GED variables of Reasoning, Math and Language skill correlate highly among themselves, disproving an often postulated dichotomy between mathematical skills and verbal (language) skills. They also correlate strongly with the Intellect factor (drawn from Table 1, column 2), whence they easily merge with that factor in an extended factor analysis. The same may be said about Special Vocational Preparation (SVP). Among the DPT complexities, only Data and People exhibit a fair correlation. Data and Things are independent, whereas People and Things correlate modestly negative. The Dexterity factor (not including the GED variables) shows an association with Things.

Table 2: Correlation among selected job requirements

\begin{tabular}{|c|c|c|c|c|c|c|c|c|c|}
\hline & Reasoning & Math & Language & SVP & Intellect & Dexterity & Data & People & Things \\
\hline Reasoning & 1.000 & & & & & & & & \\
\hline Math & 0.853 & 1.000 & & & & & & & \\
\hline Language & 0.914 & 0.836 & 1.000 & & & & & & \\
\hline SVP & 0.730 & 0.698 & 0.679 & 1.000 & & & & & \\
\hline Intellect & 0.960 & 0.898 & 0.950 & 0.738 & 1.000 & & & & \\
\hline Dexterity & 0.057 & 0.076 & -0.047 & 0.048 & 0.001 & 1.000 & & & \\
\hline Data & 0.834 & 0.785 & 0.806 & 0.687 & 0.871 & -0.005 & 1.000 & & \\
\hline People & 0.615 & 0.510 & 0.643 & 0.491 & 0.650 & -0.302 & 0.600 & 1.000 & \\
\hline Things & 0.046 & 0.040 & -0.054 & 0.016 & -0.023 & 0.728 & 0.017 & -0.247 & 1.000 \\
\hline
\end{tabular}

To explore the matching in a multivariate approach we ran regression analyses. As Table 3 shows, the Worker Functions are quite differently structured in terms of the worker requirements. As the linear specification shows, complex relations to Data and to People make high intellectual demands, whereas complex relations to Things impose no intellectual requirement. For complex relations to Things, dexterity is important, as one indeed would have expected. Relation to people also correlates negatively with dexterity. Training (SVP) is most important for functioning in relation to Data; jobs with complex relations to things do not require long vocational preparation. For proper understanding, one should note that SVP does not refer to a specific and explicit training program associated with the job. The "specific vocational preparation" may also be covered in a series of jobs preceding the present job, as in a required career profile. The non-linear specification brings most gain in explained variance for the relation to Data. Training time has a different relationship with 
each of the worker functions. Jobs that require complex functioning in relation to Data have long introductory trajectories (training or experience in other jobs). This is far less so for complex functioning in relation to Things, where the effect strongly declines at the higher levels of SVP. By contrast, the relation of People to SVP has a markedly increasing slope, indicating especially high training times for jobs that involve a very complex relation to people. Compared to the other worker functions, the relationship with SVP is least precisely estimated in case of complex relations to people, suggesting more heterogeneity than in the relationship with the other worker functions.

Considering also other specifications that we have estimated (but do not report here), the relation to Data is better explained with the available worker quality variables than the other worker functions. A specification that is fully quadratic in SVP and the two factors from Aptitudes and GED explains $82 \%$ of the variation $\left(\mathrm{R}^{2}\right)$. A linear specification with just the three GED's and SVP already gives an $\mathrm{R}^{2}$ of 0.73 . In contrast, a full quadratic on SVP and Factors, explains no more than 52\% of the variance in People, whereas just the three GED dimensions and SVP would explain 43\%. For Things, we explain 57\% of the variance with the full quadratic, whereas just the three GED's and SVP would explain a mere 6\%. Bringing in the separate Aptitude variables gives a big boost (to 52\%), adding Temperaments helps to get up to $60 \%$, using Factors rather than separate variables gives modest loss. For complexity in relation to Things, the Aptitudes are essential variables. For Data, adding Temperaments or the separate Aptitudes only modestly improves explained variation. For People, the marginal contribution of Temperaments is substantial, raising explained variance from 49 to $64 \%$ if the separate Aptitudes are included; subsuming Temperaments under factor analysis gives a large loss in explained variance. This indicates that for the complexity in dealing with people, some specific Temperaments stand out in a way that is lost in the factor analytic reduction. The important Temperaments are directing, giving instructions, and dealing with people (positive) and precise tolerances (negative).

Table 3: Worker functions explained by vocational preparation and aptitudes

\begin{tabular}{|c|c|c|c|c|c|c|}
\hline & \multicolumn{2}{|l|}{ Data } & \multicolumn{2}{|c|}{ People } & \multicolumn{2}{|c|}{ Things } \\
\hline & Coef. & $\mathrm{t}$ & Coef. & $\mathrm{t}$ & Coef. & $\mathrm{t}$ \\
\hline \multicolumn{7}{|l|}{ A: Linear } \\
\hline SVP & 0.0798 & 15.44 & 0.0475 & 9.19 & -0.0029 & 0.30 \\
\hline Intellect & 1.5262 & 124.59 & 1.2168 & 66.43 & -0.0547 & 2.41 \\
\hline Dexterity & -0.0206 & 2.42 & -0.6285 & 49.33 & 1.8907 & 119.84 \\
\hline Intercept & 2.6358 & 201.25 & 1.8971 & 96.90 & 2.2110 & 91.17 \\
\hline $\mathrm{R}^{2}$ & 0.7629 & & 0.5151 & & 0.5312 & \\
\hline \multicolumn{7}{|l|}{ B: Quadratic } \\
\hline SVP & 0.4738 & 35.36 & 0.0098 & 0.43 & 0.4770 & 17.56 \\
\hline Intellect & 1.4249 & 64.06 & 1.2750 & 33.90 & -0.4495 & -9.97 \\
\hline Dexterity & -0.2140 & -17.31 & -0.6401 & -30.62 & 1.8483 & 73.73 \\
\hline $\mathrm{SVP}^{2}$ & -0.0212 & -11.14 & 0.0089 & 2.76 & -0.0462 & -11.97 \\
\hline SVP × Intellect & -0.1199 & -12.08 & -0.0643 & -3.83 & 0.0439 & 2.18 \\
\hline SVP $\times$ Dexterity & 0.0060 & 1.42 & -0.0011 & -0.16 & 0.0063 & 0.74 \\
\hline Intellect $^{2}$ & -0.2573 & -17.49 & 0.0769 & 3.09 & -0.4312 & -14.46 \\
\hline Intellect $\times$ Dexterity & 0.1579 & 12.98 & -0.1564 & -7.60 & -0.0681 & -2.76 \\
\hline Dexterity $^{2}$ & 0.0012 & 0.17 & 0.1439 & 12.03 & -0.0937 & -6.53 \\
\hline Intercept & 2.5165 & 146.71 & 1.7893 & 61.67 & 2.1351 & 61.38 \\
\hline $\mathrm{R}^{2}$ & 0.8182 & & 0.5242 & & 0.5690 & \\
\hline
\end{tabular}


The factor analysis reported in Table 1, the correlation analysis of Table 2 and the multivariate analysis in Table 3 all illustrated how required Intellect and Dexterity are distinguishing features of jobs. By no means do they capture all aspects of a job - indeed no summary measure will ever be able to do so - but they highlight major differences between jobs. What the discussion of the structure of labour demand so far has not yet indicated is how these two factors are distributed across jobs. For this purpose, we connect the DOT information with the Census 1990 and the CPS-NBER 1990 samples, because this brings out a highly interesting feature of the US labour market. Figure 2 takes a look at the distribution of jobs, measured by Intellect and Dexterity, among male and female workers. The classical distinction between white collar intellectual and blue-collar menial jobs is visible, but the labour market is far removed from a simple dichotomy. The distributions are markedly different for men and women: the old distinction is visible for men, but it is not for women. The results are robust in the sense that they are identical for the Census data and the CPSNBER data. Obviously, this difference in the Intellect/Dexterity distributions yields a distinction between men and women in the type of jobs in regard to Data, People and Things. For reasons of space we cannot explore this further, and it would also draw the discussion into aspects of labour supply, which should be left for another time.

Figure 2: Distribution of jobs for male and female workers, 1990

\section{A: Census 1990}

Males

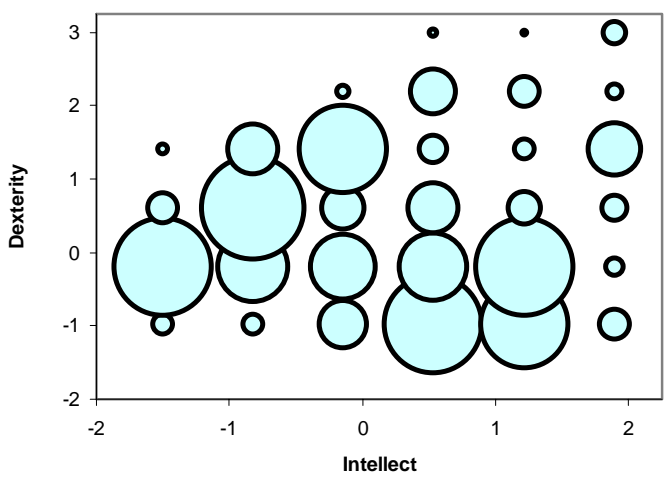

Females

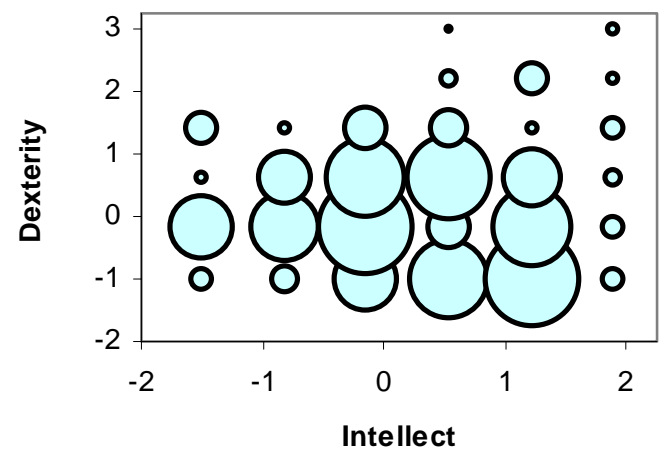


Males

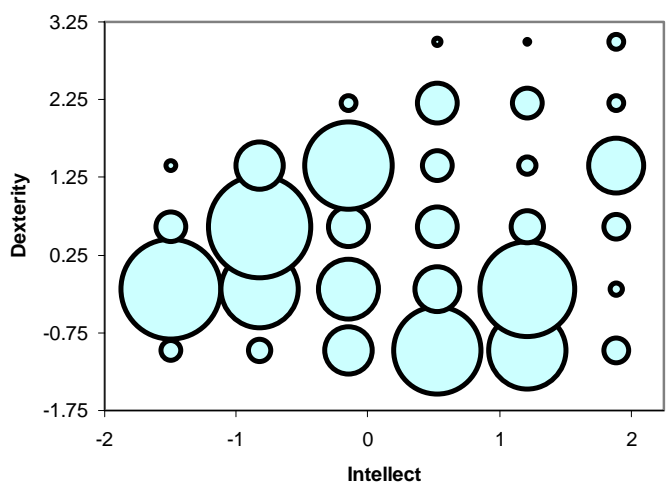

Females

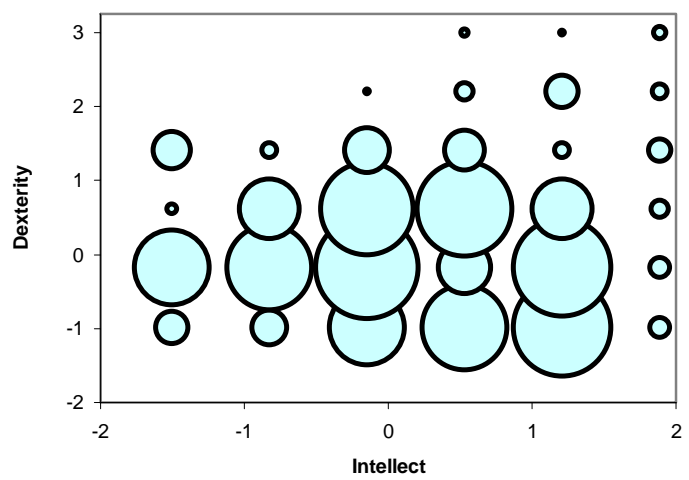

\section{Working conditions}

The DOT reports extensively on Physical burdens and Environmental conditions. Again, it is useful to consider the amount of independent variation here, and the structure of relations between variables. In the listing of Physical Demands, there are seven variables related to pure physical activities (strength, climbing, balancing, stooping, kneeling, crouching, crawling). With factor analysis, a single factor captures $74 \%$ of the variance, and the eigenvalues of the other factors are all less than 1. It has high loadings on all variables (above 0.44) and dominant loadings on climbing, stooping, kneeling, and crouching. We will call this variable the Movement factor.

There are 13 more variables under Physical Demands that can be grouped in 4 factors that jointly capture $91 \%$ of the variance. The first one loads high on Reaching and Handling, and that is how we will label it; it has very low loadings on all other variables, with one exception all virtually zero. The second factor loads high on Far Acuity and Field Vision, fairly high on Depth Perception and Color Vision, and very low on all others, so we will label it Vision. The third factor loads fairly high on Near Acuity and Fingering; we refer to it as Precision. The fourth factor loads exclusively high on Talking and Hearing, and we will label it Communication. ${ }^{7}$ The factor analysis produces a clear-cut result because of the strong demarcations in factor loadings. Each of the four factors loads high on a small number of related variables and very low if not zero on all other variables. ${ }^{8}$

There are 13 variables to characterise the environment in which the job has to be performed. Five variables describe, in a broad sense, the atmospheric conditions: exposure to the outside weather conditions, to hot and cold temperatures, to wetness and to atmospheric conditions. A single factor picks up $67 \%$ of the variance, even though its eigenvalue is less than 1 , and loads modestly on each of the variables (loadings between 0.19 and 0.55 ). We will call this factor Atmosphere.

\footnotetext{
${ }^{7}$ The fourth eigenvalue is actually less than 1 . However, the fourth factor explains 10 percent of the variance, which amounts to half of the variance unexplained by the first three factors. Furthermore, the fourth factor has a clear interpretation.

8 The other variables, not yet mentioned, are: Feeling, Tasting/Smelling, and Accommodation. Feeling and Accommodation load on the Precision factor with factor loadings that are half the size of the Near Acuity and Fingering variables. Tasting/Smelling appears to be a unique data component that we will not pursue further.
} 
There are eight other variables, but factor analysis produced no meaningful reduction here. We choose to retain six of these as separate variables: Noise, Electric Shock, High and Exposed Places, Radiation, Explosives, and Toxics. We dropped Vibrations, Move/Mechanical Parts, and Other Environmental Conditions as not sufficiently interesting to retain as a separate variable.

In Table 4, we give the correlations between our set of working conditions and the required worker qualities (we do not present the factor analyses in extenso, to save both space and the reader). Interestingly and perhaps remarkably, most correlations are very low. The groups of working conditions that we have created are quite independent and not strongly correlated to the levels of the job requirements. Clustering of working conditions is strongest for Movement, which correlates with Atmosphere and at lower levels with Noise, Shocks and Exposure. Many of the other correlations between working conditions are about zero. Atmosphere, perhaps an archetypical working condition, as exposure to hot and cold temperatures and unpleasant outside weather conditions, only correlates at more than a modest level with one variable (Movement).

Table 4: Correlations among Working Condition Variables

\begin{tabular}{|c|c|c|c|c|c|c|c|}
\hline & Movement $^{\mathrm{a}}$ & $\begin{array}{c}\text { Reach/ } \\
\text { Handling }\end{array}$ & Vision $^{\mathrm{b}}$ & Precision $^{\mathrm{b}}$ & Communic'n ${ }^{b}$ & Atmosphere ${ }^{c}$ & Noise \\
\hline Movement $^{\mathrm{a}}$ & 1.00 & & & & & & \\
\hline Reach/Handling ${ }^{\mathrm{b}}$ & $0.10 * *$ & 1.00 & & & & & \\
\hline Vision $^{\mathrm{b}}$ & $0.20 * * *$ & 0.01 & 1.00 & & & & \\
\hline Precision $^{\mathrm{b}}$ & -0.07 & 0.04 & -0.01 & 1.00 & & & \\
\hline Communication $^{\mathrm{b}}$ & $-0.29 * * *$ & -0.01 & 0.00 & 0.02 & 1.00 & & \\
\hline Atmosphere $^{\mathrm{c}}$ & $0.40 * * *$ & $0.09 *$ & $0.15 * * *$ & $-0.12 * *$ & $-0.23 * * *$ & $1.00 * * *$ & \\
\hline Noise & $0.32 * * *$ & $0.13 * * *$ & $0.28 * * *$ & -0.02 & $-0.26 * * *$ & $0.27 * * *$ & 1.00 \\
\hline Electric & $0.20 * * *$ & 0.02 & 0.04 & $0.09 *$ & -0.05 & $0.10 * *$ & 0.07 \\
\hline High/Exposed & $0.26 * * *$ & 0.02 & 0.04 & -0.01 & -0.07 & $0.22 * * *$ & 0.08 \\
\hline Radiation & -0.01 & 0.01 & -0.01 & 0.04 & 0.00 & -0.02 & -0.03 \\
\hline Explosives & 0.04 & 0.01 & 0.07 & 0.02 & -0.01 & $0.14 * * *$ & 0.05 \\
\hline Toxic/Caustic & 0.08 & 0.01 & 0.03 & 0.03 & -0.06 & $0.16 * * *$ & 0.06 \\
\hline
\end{tabular}

\begin{tabular}{lccccc} 
& Electric & High/Exposed Radiation & Explosives & Toxic/Caustic \\
\hline Electric & 1.00 & & & & \\
High/Exposed & $0.30^{* * *}$ & 1.00 & & & \\
Radiation & 0.06 & 0.00 & 1.00 & & \\
Explosives & 0.07 & $0.11^{* *}$ & 0.00 & 1.00 & \\
Toxic/Caustic & 0.05 & $0.13^{* * *}$ & 0.00 & $0.14^{* * *}$ & 1.00 \\
\hline
\end{tabular}

Notes: $\quad{ }^{\mathrm{a}}$ Factor score resulting from a factor analysis on physical activities variables

${ }^{\mathrm{b}}$ Factor score resulting from a factor analysis on physical demands variables

${ }^{\mathrm{c}}$ Factor score resulting from a factor analysis on job environment variables

*** significant at 1 percent level

** significant at 5 percent level

* significant at 10 percent level

It is often alleged that there exist correlations between worker qualities (as reflected in level of education) and amenities on the job. High wage workers are supposed to be able to buy better working conditions by accepting a lower wage. Conversely, poor working conditions (fumes, noise, toxics) should predominantly affect low wage manual workers who cannot afford to buy improvements in their working environment. Table 5 presents correlations between working conditions and worker functions (Data, People, Things) and aptitudes (SVP, Intellect, Dexterity). Note that there are good reasons to distinguish between the factors based on Physical Burdens 
(the first five variables in Table 4) and the Environmental Conditions (the last seven variables). Environmental conditions may be seen as the classical job disamenities that workers want to avoid, whereas high levels of Physical Burdens and Demands to many may not be unpleasant at all. Many people will like communication, precision work, moving around rather than sedentary work, etc.

High requirements on the Intellect factor come with high scores on Communication, and the same holds for high levels of involvement with Data and People. There is also a substantial positive correlation between the Intellect and Precision factors. The correlations between the Intellect factor and Movement, Reaching/Handling, Atmosphere and Noise are negative but smaller. All the other correlations are very low. Exposure to radiation and to explosives are independent of the job level as measured by intellectual or dexterity requirements. It is true that the intellectual factor correlates negatively with unpleasant working conditions, and the dexterity factor correlates positively, evoking the image of "good" white-collar jobs and "bad" blue-collar jobs, but the correlations are quite low. Poor worker conditions are therefore not associated merely with jobs with low intellectual requirements or high dexterity (or manual) requirements. We see little evidence of an income effect. If we take the Intellect factor as an indication of job level, then Atmosphere and Noise correlate negatively with job level. The other environmental conditions are independent. Among the Physical Burdens/ Demands, both positive and negative correlations occur

Table 5: Correlation of Worker Functions and Aptitudes with Working Conditions.

\begin{tabular}{|c|c|c|c|c|c|c|}
\hline & Data & People & Things & SVP & Intellect & Dexterity \\
\hline Movement & $-0.27 * * *$ & $-0.25 * * *$ & $0.18 * * *$ & $-0.13 * * *$ & $-0.33 * * *$ & $0.22 * * *$ \\
\hline Reach/Handling & $-0.33 * * *$ & $-0.34 * * *$ & $0.19 * * *$ & $-0.34 * * *$ & $-0.38 * * *$ & $0.25 * * *$ \\
\hline Vision & $-0.14 * * *$ & 0.01 & $0.11 * *$ & -0.07 & $-0.11 * *$ & $0.11 * *$ \\
\hline Precision & $0.27 * * *$ & 0.02 & $0.45 * * *$ & $0.17 * * *$ & $0.29 * * *$ & $0.46 * * *$ \\
\hline Communication & $0.51 * * *$ & $0.61 * * *$ & $-0.27 * * *$ & $0.28 * * *$ & $0.55 * * *$ & $-0.32 * * *$ \\
\hline Atmosphere & $-0.21 * * *$ & $-0.17 * * *$ & 0.06 & $-0.11 * *$ & $-0.27 * * *$ & $0.12 * *$ \\
\hline Noise & $-0.24 * * *$ & $-0.20 * * *$ & $0.18 * * *$ & $-0.11 * *$ & $-0.30 * * *$ & $0.15 * * *$ \\
\hline Electric & 0.04 & -0.03 & $0.13 * * *$ & 0.05 & 0.00 & $0.15 * * *$ \\
\hline High/Exposed & -0.02 & -0.06 & 0.07 & 0.01 & -0.06 & $0.10 * *$ \\
\hline Radiation & 0.02 & 0.00 & 0.06 & 0.03 & 0.04 & 0.07 \\
\hline Explosives & -0.03 & -0.01 & 0.00 & -0.01 & -0.03 & 0.03 \\
\hline Toxic/Caustic & 0.00 & -0.04 & 0.08 & 0.00 & -0.01 & $0.10 * *$ \\
\hline
\end{tabular}

Notes $\quad * * *$ significant at 1 percent level

** significant at 5 percent level

* significant at 10 percent level

We have also run regressions to test the effect of working conditions on wages, where wages are taken from the CPS-NBER sample and from the Census sample. There is a long tradition of searching for wage compensation for unpleasant working conditions (for an overview, see Rosen, 1986). Straightforward regressions do not always support the theory, and authors reporting positive effects often take pride in the special features of their dataset or their methodological edge (cf Duncan and Holmlund, 1983; Brown, 1994). Brown (1994) argues that omitted ability bias (omitting the earnings capacity to buy better working conditions) is important, but his estimate with fixed effects on longitudinal data does not resolve the puzzles. ${ }^{9}$ With our data we can shed some light on the contradictions that appear in this

\footnotetext{
${ }^{9}$ In an interesting contribution, Gronberg and Reed (1994) argue that compensating differentials should be estimated from job duration hazard models. According to search theory, there exists an equilibrium distribution
} 
literature, but we should stress that we will not engage here in an extensive analysis of wages, as we have relegated that to a separate paper (Vijverberg and Hartog, 2005).

In Table 6 we report our results. The wage regressions also contain the two factors, Intellect and Dexterity, and the variables Data, People, Things, in a simple linear specification and alternatively in a full quadratic specification (including the interactions). The results illustrate the sensitivity to data and specification. In Section 4, we chose to retain 6 variables reflecting environmental conditions in their original DOT specification. Table 5 shows that five of these seven variables have virtually no correlation with the factors. Such independence is an ideal setting for estimating the wage effects. Indeed, any coefficient that is significant is positive and none of the estimated coefficients is significantly negative, i.e., none of the estimated wage effects rejects the theory of compensating differentials. These conclusions are not sensitive to the specification of the job requirements, i.e., whether the equation is linear or quadratic. Among the two variables that do correlate with the other job characteristics (Atmosphere and Noise), Atmosphere indeed gets a coefficient that violates the hypothesis of a compensating differential, while the coefficient for Noise is still solidly positive. The situation is different however for the factor analytic composite working conditions, i.e. the Physical Burdens/Demands. Here, we find higher correlations with job requirements (up to 0.51 for Communication with Intellect). Estimated wage effects are sometimes positive, sometimes negative. This makes sense as these conditions indeed will not uniformly be experienced as unpleasant (e.g. Communication). But for these variables, the coefficients are also more sensitive to the specification: it makes a difference whether control for other job characteristics is crude or fine, i.e., whether we distinguish between jobs with a coarse linear scale or with a more refined quadratic scale. We even find sign reversals for significant coefficients (Reach-handle and Precision, for the quadratic on CPS-NBER). The sensitivity to the controls is also manifest when we consider the patterns by gender. We only present the results for men, but we have made separate estimates for women and joint estimates for both genders. For women we find similar results as for men (robust estimates and proper signs for working conditions that are uncorrelated with job requirements), but the patterns are somewhat weaker. If we pool the observations on men and women, we find rather unstable results, e.g. a negative coefficient for both men and women separately, but a positive result for the pooled sample. This underscores the basic interpretation of the empirical literature, that finding compensating wage differentials requires very precise control for other job traits and (required) worker qualities.

We conclude that there is substantial support for wage compensation on working conditions generally perceived as undesirable. Estimating these effects was favoured by the independence of these conditions from other job traits. Atmospheric conditions is the exception, but in our data set this variable is not perpendicular to the other job traits.

Table 6 Wages and Working Conditions

Data source:

Census $1990 \quad$ CPS-NBER 1990

\begin{tabular}{lrrrrrrrr}
\cline { 2 - 8 } Job characteristics: & \multicolumn{2}{c}{ Linear } & \multicolumn{2}{c}{ Quadratic } & \multicolumn{2}{c}{ Linear } & \multicolumn{2}{c}{ Quadratic } \\
\cline { 2 - 9 } Variable $^{\mathrm{a}}$ & $\mathrm{b}$ & $\mathrm{t}$ & $\mathrm{b}$ & $\mathrm{t}$ & $\mathrm{b}$ & $\mathrm{t}$ & $\mathrm{b}$ & $\mathrm{t}$ \\
\hline Movement $^{\mathrm{b}}$ & -0.0167 & -2.85 & -0.0040 & -0.61 & -0.0010 & -0.27 & -0.0145 & -3.61 \\
Reach-Handle $^{\mathrm{b}}$ & -0.0108 & -1.15 & -0.0373 & -3.73 & 0.0184 & 3.27 & -0.0123 & -1.94 \\
Vision $^{\mathrm{b}}$ & 0.0035 & 0.81 & -0.0109 & -1.71 & 0.0440 & 15.66 & 0.0171 & 4.38
\end{tabular}

of wages for a given job characteristics bundle, rather than a single equilibrium wage. Their results are not superior to those from a conventional hedonic wage equation, however. 


\begin{tabular}{lrrrrrrrr} 
Precision $^{\mathrm{b}}$ & 0.0438 & 4.59 & 0.0045 & 0.41 & 0.0217 & 3.66 & -0.0137 & -1.98 \\
Communication $^{\mathrm{b}}$ & 0.0531 & 5.03 & -0.0324 & -2.66 & -0.0149 & -2.12 & -0.0832 & -10.18 \\
Atmosphere $^{\mathrm{c}}$ & 0.0039 & 0.40 & -0.0256 & -2.40 & -0.0235 & -3.91 & -0.0441 & -6.75 \\
Noise & 0.1074 & 11.42 & 0.1045 & 10.33 & 0.1335 & 22.59 & 0.0956 & 14.95 \\
Electric shock & 0.2857 & 3.81 & 0.3185 & 4.11 & 0.2350 & 4.70 & 0.2568 & 5.00 \\
High and exposed places & 0.1054 & 0.61 & -0.0052 & -0.03 & 0.6803 & 6.15 & 0.4739 & 4.41 \\
Radiation & -0.0492 & -0.19 & 0.4995 & 1.76 & 0.0626 & 0.39 & 0.2629 & 1.47 \\
Explosives & 0.6774 & 2.85 & 0.9131 & 3.29 & 1.1543 & 7.32 & 0.9294 & 5.25 \\
Toxic/caustic materials & -0.0324 & -0.20 & 0.0673 & 0.38 & 0.1712 & 1.60 & 0.2825 & 2.44 \\
\hline R-squared & 0.2186 & & 0.2337 & & 0.2927 & & 0.3104 & \\
Standard error of regression & 0.5406 & & 0.5355 & & 0.4587 & & 0.4530 & 73209 \\
Number of observations & 40229 & & 40229 & & 73209 & & 7 \\
\hline
\end{tabular}

Notes: a. The regression also includes the two factors Intellect and Dexterity computed from GED, GATB and Temperament variables, the worker function variable and SVP

b. Factors computed from physical demands variables.

c. Factor computed from environmental conditions variables.

From our estimates we have calculated for each individual the total value of the environmental conditions, by multiplying the score on these variables with the wage regression coefficient and than adding up. We give separate results for men and women, both for the Census data and for the CPS-NBER data (which we consider more reliable). We have plotted the values against the Intellect and the Dexterity factor in a Balloon Plot (Figure 3). The plot indicates that for men the compensation for working conditions declines in relation to the Intellect factor. So, now we do find support for the often assumed positive income effect. In the plot for Dexterity, we see much more prominent compensation at the low values of dexterity than at high values. For women there is no apparent income effect in the relation between compensating wage differentials and intellectual level of the job. Similar to the evidence for men, compensation is concentrated at the low end of the dexterity scale.

Figure 3 shows the contribution of working conditions to the wage rates, both for men and women.

Figure 3: Contribution of working conditions to Log Hourly Wages by level of intellect and dexterity

\section{A : Males}

A.1a: Compensation by Intellect, Census 1990

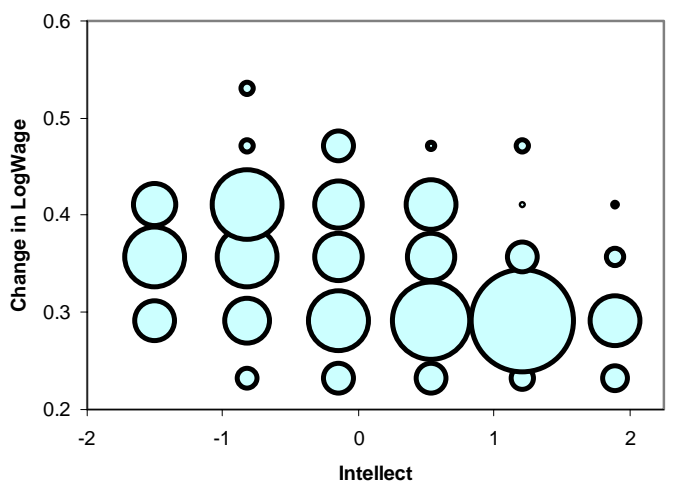

A1.b: Compensation by Dexterity, Census 1990

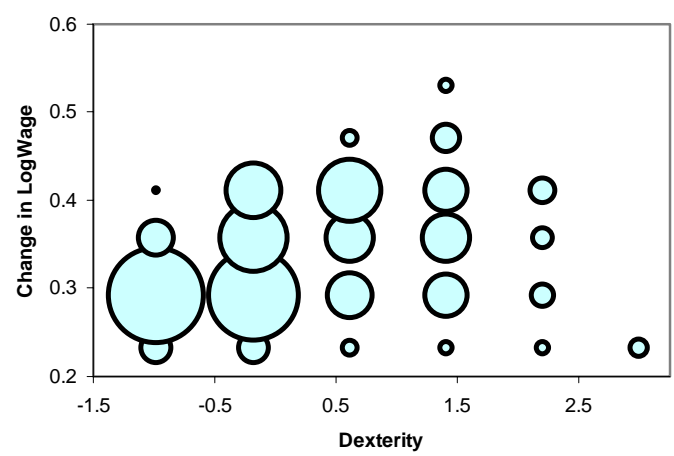


A2.a: Compensation by Intellect, CPS-NBER 1990

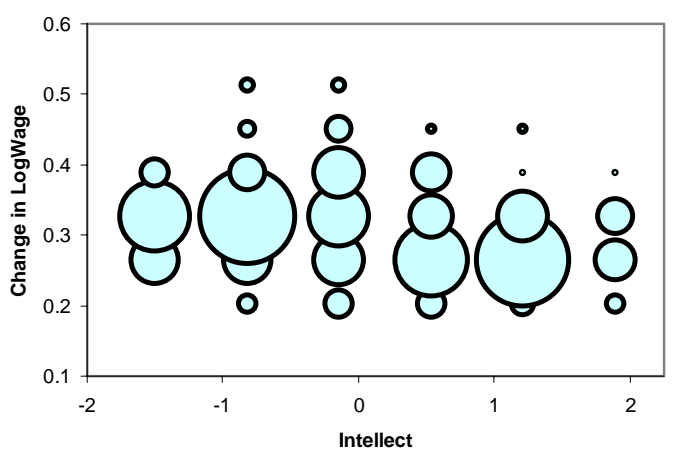

B : Females

B1.a: Compensation by Intellect, Census 1990

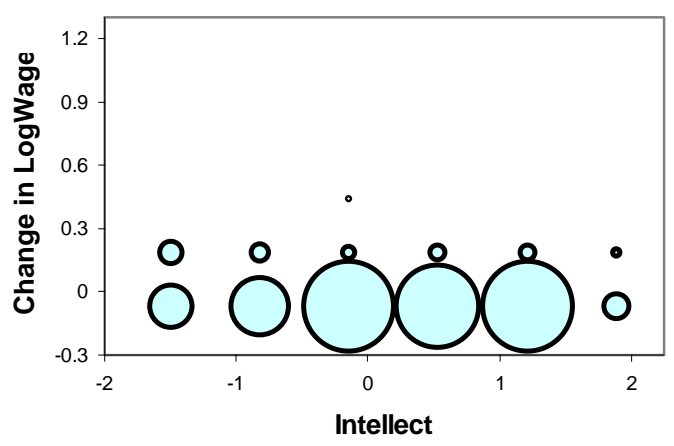

B2.a: Compensation by Intellect, CPS-NBER 1990

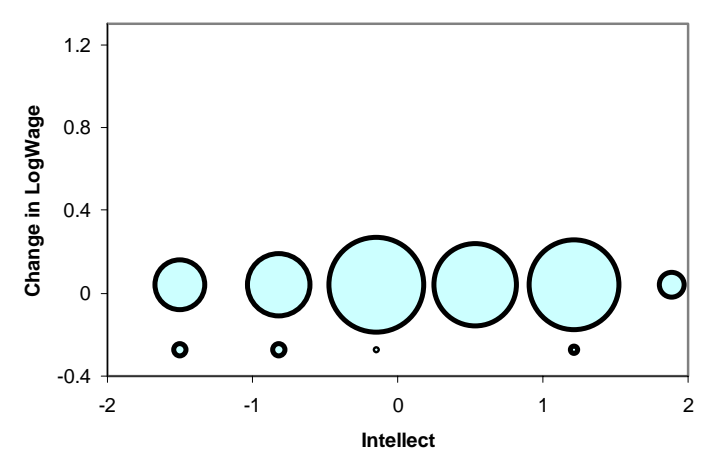

A2.b: Compensation by Dexterity, CPS-NBER 1990

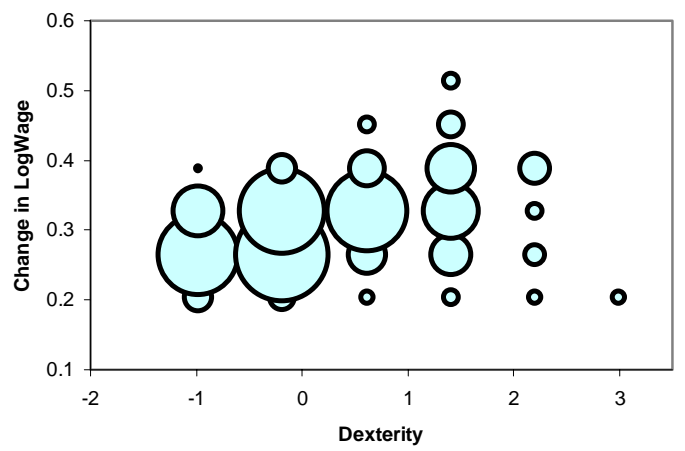

B1.b: Compensation by Dexterity, Census 1990

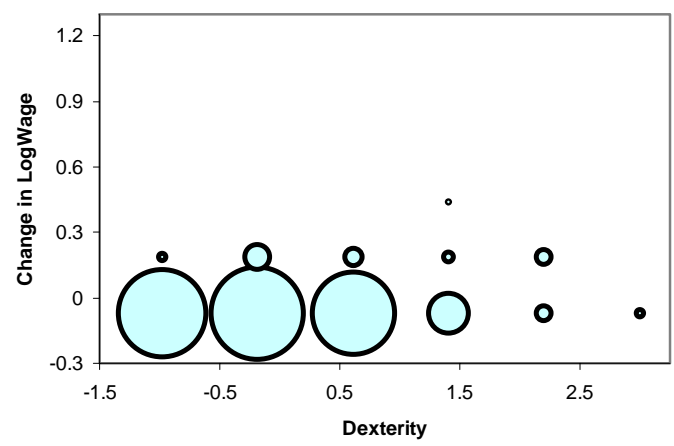

B2.b: Compensation by Dexterity, CPSNBER 1990

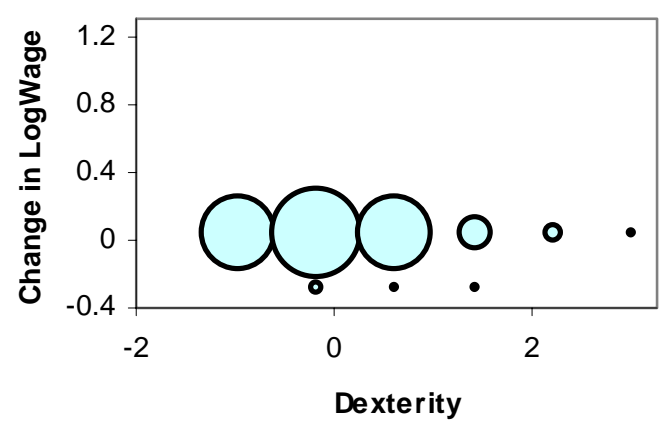

\section{Conclusion}

We are now in the position to formulate some conclusions on the structure of job requirements in the US labor market. If we take the Worker Functions specifying the degree of complexity in dealing with Data, People and Things as key variables to characterise and rank activities, then the 
relation to Things is an independent dimension. Relations to Data and People correlate, but less than perfectly, at 0.60. Aptitudes, Temperaments and the intellectual GED skills smoothly merge into two dimensions, an Intellectual factor and a Dexterity factor. The relation between Things and other variables is simple: it is Dexterity and length of the preparatory track SVP that dominate, essentially a linear relation. For People, it is Intellect $(+)$ and Dexterity (-) that count, as well as the square of Dexterity (+), thus yielding some nonlinearity. The relation to Data is most complex, with Intellect dominating, but the interactions between factors and SVP also relevant.

Jobs with lower intellectual and higher dexterity requirements may have somewhat more adverse working conditions (job amenities), but this association is fairly weak. Communication requirements correlate substantially with Data, People and the Intellectual factor, and inversely with Dexterity. Among the environmental factors, only Noise demonstrates nonzero, but still low, correlations with the skill components and worker functions; noise is more of a problem at jobs dealing with things and less at jobs dealing with data and people. By implication, those with intellectual skills work in a less noisy environment. A conclusion that fully squares with casual observation.

In our data, undesirable environmental conditions are virtually independent of other job characteristics. Under these favourable econometric conditions, we find significant wage compensation, thus supporting the theory of compensating wage differentials. The only exception to these results is Atmospheric conditions, a variable that is indeed not independent of other job traits. 


\section{References}

Brown, Charles (1994), Equalizing Differences in the Labor Market, Quarterly Journal of Economics. 94:1, 113-134.

Cain, Pamela S., and Donald J. Treiman (1981), The Dictionary of Occupational Titles as a Source of Occupational Data, American Sociological Review, 46:3, 253-278.

Eckaus, Richard S., (1965), Economic Criteria for Education and Training, Review of Economics and Statistics, 77:2, 181-190.

England, Paula, Marilyn Chassie, and Linda McCormack, (1982), Skill Demands and Earnings in Female and Male Occupations, Sociology and Social Research, 66;2, 147-168.

England, Paula, Melissa S. Herbert, Barbara Stanek Kilbourne, Lori L. Reid, and Lori McCreary Megdai (1994), The Gendered Valuation of Occupations and Skills: Earnings in the 1980 Census Occupations, Social Forces, 73:1, 65-99.

Farkas, George, Paula England, Keven Vicknair, and Barbara Stanek Kilbourne (1997), Cognitive Skill, Skill Demands of Jobs, and Earnings among Young European American, African American, and Mexican American Workers, Social Forces, 75:2, 913-938.

Filer, Randall K. (1989), Occupational Segregation, Compensating Differentials, and Comparable Worth, In Robert T. Michael, Heidi I. Hartmann, and Brigid O=Farrell, eds., Pay Equity: Empirical Inquiries (Washington D.C.: National Academy Press), 153-170.

Gittleman, Maury B. and David R. Howell. (1995), Changes in the structure and quality of jobs in the United States: Effects by race and gender, 1973 - 1990, Industrial and Labor Relations Review. 48:3, 420-440.

Gronberg, Timothy J. and W. Robert Reed. (1994), Estimating workers' marginal willingness to pay for job attributes using duration data, Journal of Human Resources. 29:3, 911-931

Hartog, Joop, (1980), Earnings and Capability Requirements, Review of Economics and Statistics, 62:2, 230-240.

Hartog, Joop (1981), Personal Income Distribution: A Multicapability Theory. (Dordrecht, the Netherlands: Martinus Nijhoff Publ.).

Kilbourne, Barbara, Paula England, and Kurt Beron (1994), Effects of Individual, Occupational, and Industrial Characteristics on Earnings: Intersections of Race and Gender, Social Forces, 72:4, 1149-1176.

Kilbourne, Barbara Stanek, Paula England, George Farkas, Kurt Beron, and Dorothy Weir (1994), Returns to Skill, Compensating Differentials, and Gender Bias: Effects of Occupational Characteristics on the Wages of White Women and Men, American Journal of Sociology, 100:3, 689-719. 
Lucas, Robert E.B. (1977), Hedonic Wage Equations and Psychic Wages in the Returns to Schooling, American Economic Review, 67:4, 549-558.

McLaughlin, Steven (1975), Occupational Characteristics and the Male/Female Income Differential. Ph.D. Dissertation, Department of Sociology, Washington State University, Pullman, WA.

Miller, Ann R., Donald J. Treiman, Pamela S. Cain, and Patricia A. Roos, eds. (1980), Work, Jobs, and Occupations: A Critical Review of the Dictionary of Occupational Titles. (Washington, D.C.: National Academy Press).

Murnane, Richard J., John B. Willett, and Frank Levy (1995), The Growing Importance of Cognitive Skills in Wage Determination, Review of Economics and Statistics, 77:2, 251-266.

National Occupational Information Coordinating Committee, NOICC Master Crosswalk database, http://www.state.ia.us/government/wd/ncdc/xw_doc.html.

Parcel, Toby L. (1989), Comparable Worth, Occupational Labor Markets, and Occupational Earnings: Results from the 1980 Census, In Robert T. Michael, Heidi I. Hartmann, and Brigid $\mathrm{O}=$ Farrell, eds., Pay Equity: Empirical Inquiries (Washington D.C.: National Academy Press), 134-152.

Parcel, Toby L., and Charles W. Mueller (1989), Temporal Change in Occupational Earnings Attainment, 1970-1980, American Sociological Review, 54:4, 622-634.

Roos, Patricia A., and Donald J. Treiman (1980), DOT Scales for the 1970 Census Classification, In Miller, Ann R., Donald J. Treiman, Pamela S. Cain, and Patricia A. Roos, eds., Work, Jobs, and Occupations: A Critical Review of the Dictionary of Occupational Titles. (Washington, D.C.: National Academy Press).

Rumberger, Russell W. (1981), The Changing Skill Requirements of Jobs in the U.S. Economy, Industrial and Labor Relations Review. 34:4, 578-590.

Shu, Xiaoling; Pi-Ling Fan, Xiaoli Li and Margaret Mooney Marini. (1996), Characterizing occupations with data from the Dictionary of occupational titles, Social Science Research. $25,149-173$.

Sorensen, Elaine (1989), Measuring the Effect of Occupational Sex and Race Composition on Earnings, In Robert T. Michael, Heidi I. Hartmann, and Brigid O=Farrell, eds., Pay Equity: Empirical Inquiries (Washington D.C.: National Academy Press), 49-69.

Temme, Lloyd (1975), Occupation: Meanings and Measures. (Washington, D.C.: Bureau of Social Science Research).

Thurow, Lester, and Robert E.B. Lucas (1972), The American Distribution of Income: A Structural Problem, Joint Economic Committee, Congress of the United States (Washington D.C.: U.S. Government Printing Office).

U.S. Department of Labor (1991). Dictionary of Occupational Titles, $4^{\text {th }}$ revised ed. 
(Washington, D.C.: U.S. Government Printing Office).

Vijverberg, W.P.M. and J. Hartog (1999), Wages, Skills, and Education: Evidence from Census Data, Paper presented at the Western Social Science Association Meeting, Fort Worth, April. 